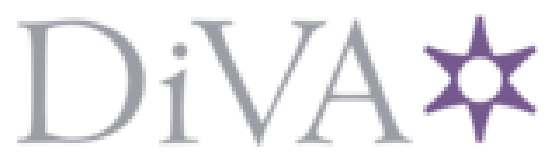

http://www.diva-portal.org

This is the published version of a paper published in Vård $i$ Norden.

Citation for the original published paper (version of record):

Johansson, E., Roxberg, Å., Fridlund, B. (2008)

Nurses' consolation: a grounded theory study.

Vård i Norden, 28(2): 19-22

Access to the published version may require subscription.

N.B. When citing this work, cite the original published paper.

Permanent link to this version:

http://urn.kb.se/resolve?urn=urn:nbn:se:hh:diva-1869 


\title{
Nurses' consolation: A grounded theory study
}

\author{
Elsie Johansson RNT, MScN, lecturer, doctoral candidate - Åsa Roxberg RNT, PhD, senior lecturer \\ - Bengt Fridlund RNT, PhD, professor
}

\section{ABSTRACT}

To date, consolation has not been clearly defined in nursing science. The purpose of this study was to identify the phenomenon of consolation from the perspective of practising nurses. Data from interviews with 21 nurses were analysed by means of the grounded theory approach. Consolation comprised supportive consolation, avoiding consolation, insufficient consolation and inaccessible consolation, which were integrated into the nurses' professional approach and personal outlook. More basic research is required in order to illuminate the meaning of the phenomenon of consolation with focus on supportive consolation as well as the non-consolation phenomenon comprising the so-called avoiding, insufficient and inaccessible consolation. In order for nurses to be able to prescribe, carry out and evaluate consoling care which alleviates patient suffering, there is a need for further knowledge of what constitutes and does not constitute consolation.

KEY WORDS: caring, consolation, grounded theory, nursing, suffering

\section{Introduction}

Today, nurses are expected to relieve patients' suffering by means of consolation in order to provide high quality care (1). Consolation is defined by nurses among others as caring and non-caring consolation (2). Caring consolation is achieved by, among other things, mediating, bonding, being spontaneous as well as offering opportunities for rest (2). Non-caring consolation does not mitigate human suffering that is tacit (2). The need for consolation arises as patients suffer from feelings of anxiety, sorrow and loneliness (3-5). Consolation facilitates the encounter between the caregiver and the patient and helps to shed light on the importance of a positive outlook on life in ethically difficult life situations. The above-mentioned aspects may be compared with circumstances in which a lack of consolation renders both caregiver and patient inaccessible to each other (6). Such situations can be a matter of life or death because the patient seeks consolation not only for the present situation but also for the future $(7,8)$. When it is a matter of life or death, a caregiver with specific confirmatory qualities may be the best provider of consolation $(2,8,9)$. Traditionally, nurses have not received any clear theoretical guidance regarding consolation. Nursing theorists and theories do not describe consolation as a distinct phenomenon but instead discuss it in relation to closely related nursing phenomena such as empathy, sympathy and compassion (4). When a patient encounters a nurse, it is the nurse's responsibility to identify and reduce his/her suffering (10-13). In some cases patients encounter caregivers who have only limited experience and knowledge of suffering and who offer unreflected and insensitively administered care. Such deficiencies should be rectified by those responsible for health care (14). Suffering can be described as a struggle between the loss of one's former quality of life and acceptance of the new circumstances resulting from the illness. In cases where there is no reconciliation with the suffering, the patient may experience a deep feeling of loneliness, which in turn can lead to mental and spiritual death in which the meaning of life is questioned (15). Acceptance of suffering through which the individual develops and undergoes personal change is possible if the sufferer is acknowledged by another human being $(15,16)$. A more fundamental understanding of the meaning of consolation is necessary in order to enhance approaches to and perspectives on how to deal with it, which could contribute to a deeper appreciation of its meaning in the modern world $(3,5,9)$. The purpose of this study was to identify the phenomenon of consolation from the perspective of practising nurses.

\section{Material and methods}

\section{Design and method description}

An explorative qualitative design with a grounded theory (GT) approach and analysis was performed between 2001 and 2003. This was done in order to better understand the rather under-researched pheno- menon by means of the descriptions of individual experiences (17). Grounded theory originates in symbolic interaction, is based on people's actions and can be understood in the context of the phenomenon in terms of its meaning, origin and position in human social interaction (18)

\section{Participants}

The informants, i.e. nurses ( $\mathrm{N}=21)$, were chosen by means of strategic and theoretical sampling (17). The nurses came from both urban and rural locations in southern Sweden and represented different sexes, ages, family situations and workplaces (Table 1).

\begin{tabular}{l|l|l|l|l}
\hline \multicolumn{5}{|c}{$\begin{array}{l}\text { Table1. Socio-demographical descriptions of the participating } \\
\text { nurses (N = 21) }\end{array}$} \\
\hline Age/ & $\begin{array}{l}\text { Family } \\
\text { sears }\end{array}$ & situation & Workplace & Location \\
\hline Woman & 34 & cohabiting & casualty department & urban \\
\hline Woman & 52 & cohabiting & rehabilitation clinic & urban \\
\hline Man & 29 & cohabiting & surgical department & urban \\
\hline Woman & 42 & cohabiting & neurology department & urban \\
\hline Woman & 52 & cohabiting & cardiac department & urban \\
\hline Man & 62 & cohabiting & cardiac department & urban \\
\hline Woman & 30 & cohabiting & geriatric unit & urban \\
\hline Woman & 41 & cohabiting & school clinic & rural \\
\hline Woman & 33 & cohabiting & pulmonary unit & urban \\
\hline Woman & 45 & cohabiting & district health centre & rural \\
\hline Woman & 34 & cohabiting & palliative unit & urban \\
\hline Woman & 43 & cohabiting & maternity clinic & urban \\
\hline Woman & 50 & cohabiting & maternity clinic & urban \\
\hline Woman & 47 & cohabiting & anaesthetic clinic & urban \\
\hline Man & 23 & single living & surgical department & rural \\
\hline Man & 45 & cohabiting & operating department & urban \\
\hline Woman & 29 & single living & pulmonary unit & urban \\
\hline Man & 42 & cohabiting & rehabilitation unit & urban \\
\hline Man & 52 & cohabiting & intensive care unit & urban \\
\hline Woman & 42 & cohabiting & pediatric unit & urban \\
\hline Woman & 52 & cohabiting & psychiatric unit & urban \\
\hline & & & \\
\hline
\end{tabular}




\section{Ethical considerations}

Written ethical approval was obtained prior to the interviews from the respective hospital managers and/or heads of department of the various units. The nurses were informed both orally and in writing about the purpose of the study and that participation was voluntary and could be discontinued at any time. They were also informed that the interview would be confidential, after which the nurses gave their oral consent to participate. They were subsequently contacted by telephone to arrange a time and place for the interview. The nurses' integrity was respected by obtaining their consent and assuring them that the data would be treated confidentially.

\section{The interviews}

The interviews, including two pilot interviews in order to check the questions, were carried out by the first author at locations chosen by the informants and lasted from 30 to 60 minutes. The theme of the interviews was consolation with a holistic perspective on the human being. One of the questions was: What practical/concrete actions did you take in the situation? This was followed by additional questions: What did you feel? What did you think? What proved to be decisive for the outcome?

\section{Data analysis}

The data analysis started with the first interview and was carried out on the basis of a cause-and-effect relationship using a coding pattern developed by Strauss and Corbin (17) - the modified analysis model comprising three coding processes: open, axial and selective. The coding processes were more or less integrated with each other. The interviews were recorded and transcribed verbatim by the first author. The texts were read line by line in order to shed light on the deeper levels of meaning and also to facilitate analytical as opposed to merely descriptive thought. This process was carried out as a means of establishing codes and categories and illuminating their characteristics as well as relationships to each other. Questions put to the data were: What do the data express? What characteristics emerge and what are the relations between the categories? In the first part of the open coding process, the objective was to identify meanings within the texts and to describe them by means of a word or phrase. These words and phrases are termed substantive codes. Substantive codes with a similar content from the different interviews were grouped into abstract categories, which were given headings based on the text. These substantive codes were subsequently identified and confirmed in new data. In the second part of the coding process, i.e. axial coding, the characteristics of each category and the relations between specific categories and sub-categories emerged. The coding pattern was derived from the phenomenon, circumstances, strategies and consequences and facilitates understanding of the relationship between the categories. In the final selective coding process, the central phenomenon emerged in the two main categories or in the story line, based on how consolation appeared to the nurses in clinical practice. This structure was subsequently used as a basis for the coding paradigm in order to illuminate the connection between the two main categories and the other categories, thereby achieving new levels of validity in the data. Analytical saturation was reached after 15 interviews, although a further 6 interviews were carried out to confirm the emerging model.

\section{Results}

Consolation from the perspective of practising nurses

Consolation in interactions between nurses and patients exhibited a pattern derived from human social behaviour. Two main categories emerged: the nurse's professional approach to the patient and the nurse's personal outlook. The nurse's professional approach consisted of two categories: proximity and distance. Proximity related to the suffering patient in terms of the nurse's integration of experience, while distance indicated a lack of integration of experience. The main category associated with the nurse's personal outlook comprised two categories: activity and passivity referring to the nurse's active and passive roles in the creation of personal proximity to the suffering patient. The pattern of consolation in the nurses' strategies was characterised by four dimensions: 1) supportive consolation where consolation was necessary; 2) avoiding consolation, in which the nurse was afraid to confront the need for consolation in the context of their own life experience; 3 ) insufficient consolation in which the nurse experienced lack of time to provide consolation; 4) inaccessible consolation in which nurses and patients were unable to interact in a way that provides consolation due to a clash of personalities and to the unique nature of each care-giving situation.

\section{Supportive consolation}

It was important to develop sensitivity to the needs of the patients in various situations. Thanks to the creation of proximity and sensitivity, patients were able to retain their dignity. One nurse expressed: «...developing a feeling for what they [the patients] want and don't want...so that you don't encroach on them... You need to develop a high level of sensitivity in order to get to know the patient... advance very carefully, otherwise there will be no contact [with the patients] at a later stage...» (T). The nurses consoled by means of empathy and sympathy, making themselves available for the patients through listening, remaining silent or conversing and sitting beside the patient in peace and quiet. One nurse stated: «...I make an effort to sit close to the patient and obtain eye contact with him/her, listen... make sure to listen ... be aware of his/her situation and respond, this certainly involves empathetic ability...» $(L)$. Nurses conveyed a feeling that they were in close proximity, that they remained present and strived to understand their patients with compassion and from the heart as well as inspiring hope. In order to be able to achieve a deeper relationship with the patients, the nurses listened actively with sensitivity and supportive eye contact. They aimed to provide hope that mediated confidentiality and security. The informants reported that patients related their anxieties and burdens to them and by so doing continued to fight their illness. One nurse expressed: «...one piece of advice is that you should try to detach from yourself... from your own situation... tear yourself away from private concerns sometimes ... that you try to see the situation from other people's perspectives or from several alternative perspectives [in order to be able to provide consolation], that you make an effort in that direction...» (E). Another nurse reported: «...Consolation is also a form of encouragement... mediating hope and strengthening their feelings of hope... Conversation and body language are very important...» $(K)$. One form of consolation was to enable the patient to focus on something other than the illness and its associated problems, something positive. One nurse expressed: «... if they [the patients] have grandchildren and they are sitting on the beach... a warm summer's day and the children are sitting by the shore and the water is flowing by and the gulls are screeching...» $(N)$. Precise and correct information provided in dialogue with the patient was described as an important element of the act of consolation. It was also important to choose the right time for presenting the information. The place where the information was given, as well as how it was given and followed up, was of great importance. One nurse commented: «...there were a few advantages in that I was a little older [nurse]... they have a bit more confidence in me... it is often very individual how you tackle the situation... just using simple words [to inform]... this is important during the first few hours... trying to be purely realistic... the final thing one does is to present all the positive stuff...» $(F)$. The physical aspect of consolation was mostly described as hand contact, hugs and body massage. One nurse expressed: «... providing a hug when it feels right, embracing the patient; I don't think that everyone wants their hand held but there is always body language and contact...» $(K)$. Consoling could also be of a medical nature. One nurse stated: «... this is what one does.. some think that medical interventions are in themselves a consolation where there are many patients who [need] an injection...or sedatives ...» (I).

\section{Avoiding consolation}

On the basis of their life-experiences, the nurses avoided dealing with the patients' need for consolation. One nurse expressed: «...obviously 
when you are younger you prefer not to get involved in it ... [and console ]... you don't really want to in the beginning when it can be very difficult...» $(F)$. According to another nurse: «...If I hadn't felt certain that I could provide an answer I would probably have chosen to say 'hello' and gone away again and even if you choose to sit down [despite lack of experience], I don't know whether you can really provide the same level of consolation...» (D). The nurses thought that their awareness of consolation was strengthened by education and knowledge. However, there was a difference between theory and tried and tested experience. Consolation was not theoretically anchored in models or specific guidelines. According to the nurses, consolation was instead a natural and spontaneous reaction to the suffering of another human being. This situation carried a risk of avoiding consolation. One nurse expressed: «... I don't know what I do [when I provide consolation]... I haven't really thought about how I or other colleagues go about it [when I or colleagues offer consolation] ... because it is different every time...» $(O)$.

\section{Insufficient consolation}

The nurses stated that insufficient consolation was the result of lack of time as well as physical and psychological distance. Despite the fact that there were many other demands on them, the nurses sometimes took time to talk to patients but did not provide consolation. If there was no time, the nurses had to take care of insecure patients at a later stage. One nurse expressed: «...This is a dilemma. I know that it is necessary but I don't have time to mess around. I sometimes think that it is simpler to just go past. It is a great shame that there is no time [for consolation]...» (E). One nurse commented: «... because sometimes you're in such a hurry that you stand at the door and talk, you just don't start another conversation or offer any form of consolation...» $(K)$. The amount of time spent in close proximity to the patient differed according to his/her needs. The nurses felt that the patient should not be turned away and forced to wait for consolation but that his/her need should be met immediately. One nurse expressed: «...you can't really say that you will console them later... when a child has hurt him/herself and comes running to me... it is absurd if I say OK I will console you in two hours' time, when the pain is being experienced now, and mental pain is not something that you can put away in a box and take out later...»(U).

\section{Inaccessible consolation}

Inaccessibility concerned not being able to empathise with another person in terms of the nurse being incapable of offering consolation to the patient. A nurse expressed: «...You can't just console another person by being in close proximity to them. We can never properly understand another person ...» $(\mathrm{O})$. There were also nurses who highlighted the negative aspects of consolation, due to the fact that sympathy or empathy is not always a source of consolation to another human being. One nurse mentioned: «... that you [as a nurse] do not become too personal ... do not get too involved emotionally and keep a certain amount of distance... an awareness that feelings can easily take over $\ldots \gg(H)$. The nurses also felt that not all patients needed the consolation they offered. Instead nurses should listen, be sensitive and read the situation through being aware and asking open-ended questions, thereby identifying whether or not there is such a need. One nurse expressed: «...It's not always obvious if a person needs consoling... a some cardiovascular diseases give rise to a lot of anxiety but you do not always see it...» (E). One nurse stated: «...Some patients appreciate consoling care but others want respect for their integrity...» (I). Sometimes the nurse's state of mind was such that he/she was unable to be responsive to and empathise with the patient at the precise moment when the latter needed consolation. One nurse expressed: «...on certain days you just don't have the energy to console. It's a protective reflex that you feel that you just cannot console anymore... integrating this [suffering] and offering consolation at the same time just seems very mechanical... you hear what the patient says but that's the end of it...» $(U)$. Personal chemistry was also deemed important for mediating consolation. The nurses explained that it was not possible to encounter and create a relationship with people from every walk of life. They expressed that not all patients opened up and revealed or disclosed their thoughts and feelings but instead remained distant. One nurse expressed: «...it is personal chemistry. It must be acknowledged... that not everybody can get along. Because in the encounter one consoles the other...» $(C)$.

\section{Discussion}

\section{Methodological issues}

The methodological approach in qualitative studies involvert the following important concepts; applicability, reasonableness, trustworthiness and conscientiousness (19). Applicability is strengthened by the fact that grounded theory was considered a suitable method for the purpose of the study, due to its ability to describe real life situations as well as how nurses reflect on and mediate consolation in such complex circumstances. The grounded theory method made it easier to understand the complexity of consolation and take all social and psychological factors of human behaviour into consideration (20, 21). The model used in the study will hopefully encourage further studies, which can serve to clarify the emerging patterns of consolation within the nursing profession. The notion of applicability also refers to the strategic and theoretical sample, which facilitated a broad empirical base. There were, however, only sex male nurses in the study, which figure is representative of the number of male nurses employed by health authorities (22). The reasonableness of the interview questions was assured by pilot interviews and the relevance of the data obtained from the interviews. We are aware of the fact that the objectivity of the study could have been affected by the authors' conscious and unconscious previous experience of the nursing profession. In order to counteract these limitations, the authors attempted to maintain an inductive and open-minded approach to the interviews and the different stages of the data analysis (17), which in turn contributed to greater theoretical sensitivity (23). However, Strauss and Corbin (17) hold that the researcher's prior understanding within the area is a positive aspect in the sense that it may enhance sensitivity towards the data and analysis. Reasonableness was also ensured by the fact that the analysis was carried out in a secure manner as a result of the participants' knowledge and the authors' methodological knowledge. Trustworthiness between the data collection and subject area was ensured through step by step processing in the data analysis, continuously moving back and forth between the parts and the whole by means of comparisons between data, codes and categories. Conscientiousness was ensured by keeping the stated aim in mind in all parts of the research process.

\section{Result issues}

The findings of this study revealed that consolation is a multi-dimensional phenomenon. Consolation was identified from the perspective of a nurse's professional approach and personal outlook as supportive, avoiding, insufficient and inaccessible. Parts of supportive consolation are in agreement with previous studies pertaining to caring science, caring theology and the existential perspective (2-5). These studies highlight the fact that it is necessary that the mediator and receiver are ready for consolation. This means that the mediator of consolation must be capable of recognising suffering as well as engaged in and able to touch the inner soul of the suffering person at the precise moment at which the need for consolation is experienced. In addition, the mediator does not abandon the person who is suffering. One prerequisite for consolation is that the sufferer feels accepted as the one he or she really is. Another is the experience of close proximity which inspires hope and provides the sufferer with the courage to endure the suffering. The suffering person is acknowledged through the supportive dialogue in which the mediator is engaged in his/her suffering. The mediator inspires hope and encouragement, which in turn promotes a feeling of security and consolation. Consolation helps the suffering person to reconcile him/herself with the suffering through acceptance of being in a situation of dependency (2-5). In avoiding, inaccessible and insufficient consolation, the possibilities for the nurse to offer consolation are reduced due to human and organisational limita- 
tions. Similar approaches are touched upon in several other studies (2, $24,25)$, e.g. experience of alienation between the healthcare professional and the suffering patient. Both healthcare professionals and patients can be occupied by other experiences, feelings, thoughts and actions, which can cast a shadow over the genuine consoling encounter. In a thesis by Roxberg (2), healthcare professionals mediated consolation in the 'here and now' without guidelines and in accordance with the individual care recipient's unique experience of suffering. Furthermore, Roxberg (2) shows that avoiding consolation differs from spontaneous consolation in that the nurse momentarily disregards the need for consolation. Lanara (26) explains the concept of suffering and consolation in a similar way. To offer consolation is regarded as one of the most delicate and difficult tasks of a nurse. The willingness to mitigate the patient's suffering is not enough on its own. To console someone requires hard work, life experience, courage and love. If not mediated in an appropriate manner, consolation can be harmful and thereby create even greater suffering for the patient.

\section{Conclusions and implications}

The purpose of this study was to identify the phenomenon of consolation from the perspective of practising nurses. Consolation was visible in the nurses' professional approach and personal outlook, which were integrated into the following four strategies: 1) supportive consolation, where consolation was necessary; 2) avoiding consolation, where the nurses were afraid to confront the need for consolation due to limited life experience; 3 ) insufficient consolation in which the experience of having insufficient time to provide consolation was prominent; and 4) inaccessible consolation where the nurse and patient were unable to meet in a consoling interaction due to the clash between different personalities and the unique nature of each care situation. Further research is required on the phenomenon of consolation, with emphasis on caring, i.e. supportive, as well as non-caring consolation, characterised by avoiding, insufficient and inaccessible consolation. In order for nurses to prescribe, carry out and evaluate consoling care which alleviates patient suffering, there is a need for further knowledge of what consolation is and what it is not.

\section{Accepted for publication 06.02.2008}

Elsie Johansson RNT, MScN, lecturer, doctoral candidate (1), Åsa Roxberg RNT, PhD, senior lecturer (2) and Bengt Fridlund RNT, PhD, professor $(1,2)$

(1) School of Social and Health Sciences, Halmstad University, PO Box 823, SE - 30118 Halmstad

(2) School of Health Sciences and Social Work, Växjö University, SE - 35195 Växjö

Correspondence: Elsie Johansson, School of Social and Health Sciences, Halmstad University, PO Box 823, SE - 30118 Halmstad, elsie.johansson@hh.se

\section{References}

1. Lövgren G. A policy for good care - does it matter? An intervention in Västerbotten County Council [dissertation]. Umeå: Umeå University; 2000.

2. Roxberg Å. Caring and non-caring consolation [dissertation]. Vasa: Åbo Academy; 2005.

3. Mattsson - Lidsle B, Lindström UÅ. Consolation - a conceptual analysis. Nordic Journal of Nursing Research and Clinical Studies 2001; 21(3):47-50

4. Mattson B. Comfort - a healing force in the embrace of communion [master's thesis]. Vasa: Åbo Academy; 1999.

5. Norberg A, Bergsten M, Lundman B. A model of consolation. Nursing Ethics 2001; 8(6):544-553.

6. Söderberg A, Gilje F, Norberg A. Transforming desolation into consola- tion: the meaning of being in situations of ethical difficulty in intensive care. Nursing Ethics 1999; 6(5):358-373.

7. Söderberg A, Norberg A, Gilje F. Meeting tragedy: interviews about situations of ethical difficulty in intensive care. Intensive and Critical Care Nursing 1996; 12:207-217.

8. Talseth AG, Gilje F, Norberg A. Being met - A passageway to hope for relatives of patients at risk of committing suicide: A phenomenological hermeneutic study. Archives of Psychiatric Nursing 2001; 6(15):249-256.

9. Alfredson E, Wiren B, Lutzen K. Comfort - a wave of well wishes and wellbeing. A qualitative investigation of the experience of comfort in the elderly. Nordic Journal of Nursing Research and Clinical Studies 1995; 2:34-39.

10. The National Swedish Board of Health and Welfare. Service competence demands for RN. Stockholm: The National Swedish Board of Health and Welfare (2005-05-1) [cited 2005 Feb]. www.socialstyrelsen.se (In Swedish).

11. The National Swedish Board of Health and Welfare. General advice about care within Swedish health and medical services (SOSFS 1993:17). Stockholm: The National Swedish Board of Health and Welfare; 1993. (In Swedish)

12. International Council of Nurses (ICN). The ICN Code of Ethics for Nurses (2000) [cited $2005 \mathrm{Feb}$ ]. www.icn.ch

13. Eriksson K. Caring science as an academic discipline. Vasa: Åbo Academy; 2001.

14. Dahlberg K. The unnecessary suffering from care. Nordic Journal of Nursing Research and Clinical Studies 2002; 22:4-6.

15. Eriksson K. Encountering suffering. Vasa: Åbo Academy; 1993.

16. Ekstedt M, Fagerberg I. Lived experiences of time preceding burnout. Journal of Advanced Nursing 2005; 49(1):59-67.

17. Strauss A, Corbin J. Basics of qualitative research techniques and procedures for developing grounded theory. London: Sage Publications; 1998.

18. Blumer H. Symbolic interactionism perspective and method. California: University of California Press Berkely and Los Angles; 1986.

19. Fridlund B, Hildingh C. Qualitative research methods in the service of health. Lund: Studentlitteratur; 2000.

20. Munhall PL, Oiler Boyd C. Nursing research: A qualitative perspective $2^{\text {nd }}$ Ed. In: Hutchinson SA, Grounded Theory: The method. New York: National League for Nursing Press; 1993 p. 180-211.

21. Munhall PL. Nursing research: A qualitative perspective 3rd Ed. In: Hutchinson SA, Wilson S H. Grounded Theory: The method. New York: National League for Nursing Press; 2001 p. 209-243.

22. Strömberg B. Professional attitudes of doctors and nurses. A study of conceptions [dissertation]. Göteborg: University of Göteborg; 1997.

23. Starrin A, Dahlgren L, Larsson G, Styrborn S. Along the path of discovery. Qualitative methods and grounded theory. Lund: Studentlitteratur; 1998.

24. Hellzen O, Asplund K. Being in a fragmented isolated world: interviews with carers working with a person with a severe autistic disorder. Journal of Advanced Nursing 2002; 37 (4):346-354.

25. Rasmussen Holritz B. In pursuit of a meaningful living amidst dying: Nursing practice in a hospice [dissertation]. Umeå: Umeå University; 1999.

26. Lanara V. Heroism as a nursing value. A philosophical perspective [dissertation]. Athens: Publications of Sisterhood Evniki Athen; 1981. 